\title{
Inflammatory Breast Cancer: A Literature Review
}

\author{
Fouzia Mamouch ${ }^{\mathrm{a}, \mathrm{b}, \mathrm{c}}$, Narjiss Berrada ${ }^{\mathrm{b}}$, Zineb Aoullaya, ${ }^{\mathrm{a}}$, \\ Basma El Khanoussi ${ }^{b}$, Hassan Errihani ${ }^{a, b}$
}

\begin{abstract}
The multidisciplinary management of inflammatory breast cancer (IBC), which is the most aggressive form of breast cancer due to its rapid proliferation, has changed over the past three decades thanks to advances in medical treatments that represent the basis of treatment, without eliminating the use of locoregional treatments including surgery and radiotherapy in the localized stages. The molecular profile determination of IBC allows the orientation towards new targeted therapeutic strategies with an impact on survival.
\end{abstract}

Keywords: Inflammatory breast cancer; Treatment; Molecular profile

\section{Introduction}

Inflammatory breast cancer (IBC) is a rare and aggressive clinicopathological entity of breast cancer. It represents $1 \%$ to $6 \%$ of all cases of breast cancer [1]. The first description of IBC in the scientific literature was published in 1814 by Sir Charles Bell [2], then in 1938 the terms "true IBC" and "primary IBC" were coined to distinguish what is now considered "IBC" and "secondary IBC". Secondary IBC was defined by secondary changes in the breast or recurrence of breast cancer [3]. The incidence of IBC varies considerably in different regions around the world. Studies have shown that IBC is more common in North Africa than in other parts of the world; the most recent estimates suggest that it represents $5 \%$ to $7 \%$ of all breast cancers in Tunisia [4], 4\% to $5 \%$ in Morocco [5], while in Egypt it has a rate of $11 \%$ [6]. IBC is also characterized by rapid progression and higher metastatic potential [2]. The 5-year survival of patients with this cancer type is low compared to other breast cancers [7]. However, the combinations of neoadjuvant chemotherapy, surgery and radiotherapy led to an improvement in prognosis. Optimal management of IBC requires coordination between oncologists, surgeons and radiation therapists [2]. The present study aims to provide an update on clinical, mo-

Manuscript submitted October 10, 2018, accepted October 25, 2018

aMohammed V University, Rabat, Morocco

bNational Institute of Oncology, Rabat, Morocco

${ }^{\mathrm{c}}$ Corresponding Author: Fouzia Mamouch, Mohammed V University, Rabat,

Morocco. Emaill: fouziamamouch@gmail.com lecular and therapeutic specificities of IBC.

\section{Literature Search}

The reviewed studies were identified through PubMed, Google Scholar and Science Direct research using the combination of the following terms for both French and English languages: inflammatory breast cancer; breast cancer; neoadjuvant chemotherapy; clinical presentation, molecular profile and treatment. For each study, abstracts was read and included based on its relevance and had to meet the following criteria: 1) To be focused on IBC; 2) To consider new biomarkers of IBC; 3) To be majorly based on the recent studies.

Accordingly, selected studies were then read and evaluated for inclusion. Only studies on breast cancer survivor, behavior or quality of life were included. Given that this pathology is rare, references of the selected studies were also reviewed and considered for inclusion. At the end, only 50 articles and abstracts were included in the examination.

\section{What Are IBC's Risk Factors?}

Currently, there are no established risk factors for IBC. However, many epidemiological studies clarify the characteristics of IBC that have been studied. The most important suspected risk factors associated with this disease are: black race, body mass index (BMI), age and region [8]. In fact, African-American women have an IBC incidence at least 50\% higher than Caucasian [9]. Also, high BMI and young age at the emergence of this disease have been identified as risk factors [8]. Additionally, North African countries have reported a higher percentage of IBC cases than other regions. Historical reports from Tunisia had recorded the highest incidence in the word with $50 \%$ of newly diagnosed cases of breast cancer [10]. The use of a more uniform approach in classification criteria had led to a better distinction between IBC and neglected locally advanced breast cancer. The estimated incidence in this region is now comprised between $5 \%$ and $10 \%$ [4]. Also, some recent reports suggested that the westernization of the population habits had played a role of the change observed of the global profile of breast cancer in North Africa.

\section{IBC Diagnosis Criteria}

At present, there are no definitive molecular or pathological 
Table 1. Comparison Between Studies Concerning Molecular Classification of Inflammatory Breast Cancer Subtypes [15-19]

\begin{tabular}{|c|c|c|c|c|c|}
\hline & $\begin{array}{l}\text { Francois et al } \\
2005[15](\%)\end{array}$ & $\begin{array}{l}\text { Nabila et al } \\
2011[16](\%)\end{array}$ & $\begin{array}{l}\text { Neyran et al } \\
2015[17](\%)\end{array}$ & $\begin{array}{l}\text { Tina et al } 2016 \\
{[18](\%)}\end{array}$ & $\begin{array}{l}\text { Sarah et al } \\
2017[19](\%)\end{array}$ \\
\hline \multicolumn{6}{|c|}{ Dermal lymphatic emboli } \\
\hline Absent & 30 & - & - & - & - \\
\hline \multicolumn{6}{|l|}{ Type } \\
\hline \multicolumn{6}{|l|}{ Grade } \\
\hline $\mathrm{I} / \mathrm{II}$ & 35 & 63.3 & 29.5 & 30 & 12.5 \\
\hline III & 65 & 36.7 & 53.6 & 70 & 81.5 \\
\hline \multicolumn{6}{|l|}{ Subtypes } \\
\hline
\end{tabular}

diagnosis criteria for IBC. Therefore, the diagnosis is entirely based on clinical symptoms such as the rapid onset of signs like erythema and edema of the breast skin (orange peel), i.e. the possibility of misleading between IBC and benign bacterial infections such as mastitis is high, that is why it is important to note that IBC is not usually associated with symptoms of infection such as fever [11].

\section{Clinical criteria}

According to the American Joint Committee on Cancer, The New Edition (seventh) AJCC Staging System for Breast Cancer, the signs and symptoms required for IBC diagnosis are erythema occupying at least one-third of the breast, edema and/ or orange peel of the breast, and/or a warm breast. A palpable mass is present in only one-third of cases. The onset of these signs and symptoms should be rapid; the length of the time taken during its initial presentation should be 3 months [12]. These criteria are important to distinguish the skin changes of IBC (T4d) from the skin changes associated with a neglected noninflammatory breast tumor (T4a-c).

\section{Pathological criteria}

IBC is not considered as a specific histological subtype of breast carcinomas, and it has no specific diagnostic pathologi- cal criteria. Most IBC are ductal carcinoma and had a high histological nuclear grade [13]. About $17 \%$ to $30 \%$ of IBC cases are triple negative and $18 \%$ to $44 \%$ are epidermal growth factor receptor 2 (HER2) positive [14] (Table 1, [15-19]). The combination of histopathological breast data with the characteristic clinical features may confirm the diagnosis of IBC. Dermal lymphatic emboli are present in approximately $75 \%$ of cases. There is no direct correlation between the presence, number, or size of emboli and the degree of redness of the skin in patients with IBC [20]. Although cutaneous pathological evidence of nodal invasion is not considered as a definitive diagnostic endpoint for IBC, skin biopsy is recommended in case of suspicion as an aid to diagnosis, and the absence of dermal emboli does not exclude the diagnosis [21].

\section{Molecular criteria}

Studies have suggested that IBC does not have a specific molecular signature. Recently, they have identified in vivo and in vitro genes that can contribute to the aggressive phenotype of IBC (Table 2) [15].

In addition, authors have reported that cell proliferation genes are more strongly associated with IBC than non-IBC; and those genes for tumor processes, including the signaling pathway associated with inflammation, cellular transformation, and angiogenesis, are altered more in IBC than in nonIBC [22]. About $80 \%$ of IBC tissue samples are characterized

Table 2. The Genes Associated to IBC Phenotype

\begin{tabular}{ll}
\hline Cluster & Genes \\
\hline Estrogen receptor (ER) & ESR1, GATA3, XBP1, HNF3A, MUC1 and CCND1 \\
ERBB2 & ERBB2 and GRB7 \\
Basal & KRT5 and TRIM29 \\
\hline
\end{tabular}


by a loss of WNT1-inducible-signaling proteins 3 pathway (WISP3) which are cysteine-rich proteins and which play a role in inhibiting the invasive potential and the angiogenesis of IBC cells in tissue cultures and animal models [23]. Furthermore, lymphovascular emboli of IBC are characterized by overexpression of a number of genes, such as homologues of the C-guanosine triphosphatase family (RhoC-GTPase) and $E$-cadherin [23, 24]. IBC cells are characterized by overexpression of $E$-cadherin, which is essential for cell adhesion, tumor emboli formation, and progression of metastasis which implies poor prognosis $[25,26]$. In addition, RhoC-GTPase is overexpressed in $90 \%$ of IBC tumors compared to $38 \%$ of nonIBC tumors. Indeed, RhoC-GTPase plays a critical role in the metastatic behavior of IBC by increasing all aspects of metastatic processes such as motility and cell invasion, cytoskeletal assembly, and cell adhesion [26]. However, all the above mentioned markers do not distinguish IBC from non-IBC and fail to explain the specific pathophysiology of IBC. The latter had a significantly higher expression of $\mathrm{Ki}-67$ and genes associated with metabolic pathways and lipid signaling [27]. An in vitro study revealed that epithelial-mesenchymal transition (EMT) is associated with IBC cell line cell migration and invasion [28], and much emphasis has been placed on determining the role of EMT in tumor progression and metastasis in IBC [29]. Other studies have reported that the epidermal growth factor receptor (EGFR) that is involved in the pathway of tumor growth and IBC metastasis through EMT and EGFR expression is an independent factor in prognosis [30].

\section{Radiology in IBC}

Significant advances in imaging techniques have improved the diagnosis and classification of IBC, therefore, in women with suspected IBC, imaging the primary breast tumor helps to facilitate diagnosis, biopsy, evaluate the response to treatment but also to provide screening of the contralateral breast [12, $31]$. It is well documented that $20 \%$ to $30 \%$ of newly diagnosed IBC women have distant metastases at the time of diagnosis; imaging may also be useful in identifying these distant metastases [32].

Mammography is the current standard imaging. The optimal compression can be limited by the pain related to breast's inflammation. As in other types of breast cancer, mammography can reveal several changes such as skin thickening, stromal infiltration, architectural disorganization or diffuse increase in density. The tumor mass is absent in $25 \%$ of cases [33].

Ultrasound also provides valuable information about regional lymph nodes, including axillary nodes and supraclavicular nodes [34].

Breast magnetic resonance imaging (MRI), has the highest sensitivity in the detection of primary mammary parenchymal lesions and global skin abnormalities. It's also helpful to guide skin biopsies. On MRI, the thickening of the skin is visible in $90 \%$ to $100 \%$ of patients with IBC; thus, MRI can be a useful tool for differentiating patients with IBC from patients with locally advanced (non-IBC) cancer. A study from the University of Texas MD Anderson Cancer demonstrated that for IBC, breast MRI identifies all breast parenchymal lesions, while mammography identifies $80 \%$ of breast parenchymal lesions and ultrasound identifies $95 \%$ of lesions of the mammary parenchyma [35]. Because of its high sensitivity, MRI is highly recommended in patients suspected of IBC and is a useful method for monitoring the response to chemotherapy (Fig. 1).

\section{Treatment}

Historically IBC was treated by surgery and/or radiotherapy. The 5-year overall survivals were under 5\% [36]. Before 1950, the median survival for patients treated by mastectomy was 19 months, none of the patients survived to 5 years [37]. The use of definitive radiotherapy without surgery showed a 5-year survival rate without recurrence and overall survival rate of $17 \%$ and $28 \%$, respectively. The combination of surgery and radiotherapy leads to the improvement of overall survival [38]. The introduction of systemic chemotherapy showed additional survival benefit. The trimodal therapy including chemotherapy, surgery and radiotherapy became the standard of care of IBC. In December 2008, The First International Conference on Inflammatory Breast Cancer developed guidelines for the management of IBC [39].

For metastatic disease, the treatment is based on chemotherapy with/without target therapy. Surgery and radiotherapy are used only to control palliative symptoms (Fig. 2).

\section{Chemotherapy}

Due to the rarity of the disease, there is no prospective randomized clinical trial for IBC. Available data come from retrospective series, centers experiences and cohorts in randomized trials. In a study from MD Anderson with 178 IBC patients, anthracycline-based chemotherapy followed by local treatment with irradiation, with or without mastectomy led to an improvement of overall survival rate at 5 years to $40 \%$ and 10 years survival to $33 \%$ [40]. The integration of taxanes into chemotherapy has shown efficacy in the neoadjuvant treatment of IBC. In a cohort study of 68 patients with IBC in two prospective randomized trials, treatment with either three cycles of FEC (cyclophosphamide, epirubicin and 5-fluorouracil), then taxanes followed by surgery, adjuvant therapy, and radiotherapy have resulted in overall 5-year survival rate of $44 \%$ and 10 years survival of $32 \%$ [41]. The standard of care in neoadjuvant is a sequential regimen using anthracyclines then taxanes.

\section{Targeted therapy}

In IBC, HER 2 is overexpressed in $36 \%$ to $60 \%$ of IBC cases [42]. For the treatment of localized breast cancer, only monoclonal antibodies for HER-2 have been shown to be efficacious. In the NOAH study, which includes IBC patients, the addition of trastuzumab to systemic therapy significantly improved the pathological complete response (pCR) rates $(38 \%$ versus $19 \%, \mathrm{P}=0.001$ ) and event-free survival (3-year event- 


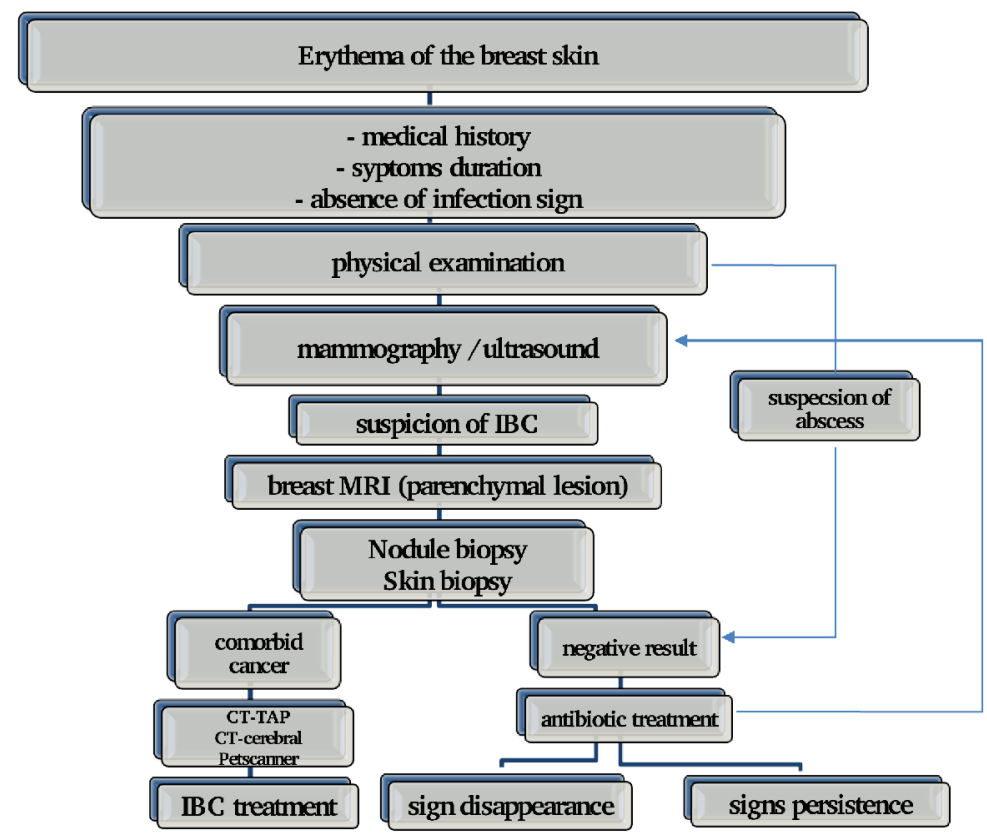

Figure 1. Approach upon IBC diagnosis.

free survival $71 \%$ versus $56 \%$, HR $0.59, \mathrm{P}=0.013$ ) [43]. The use of double blocking with trastuzumab and pertuzumab in the neoadjuvant sitting had improved the rate of pCR. In the NeoSphere and TRYPHAENA trials the pCR rate was $45.8 \%$ and $50.7 \%$ respectively $[44,45]$. The studies with lapatinib, a tyrosine kinase inhibitor of EGFR and HER-2, failed to demonstrated efficacy [46]. Moreover, the anti-angiogenic therapies (bevacizumab and semaxanib) have shown only modest clinical effect in the clinical trials [47].

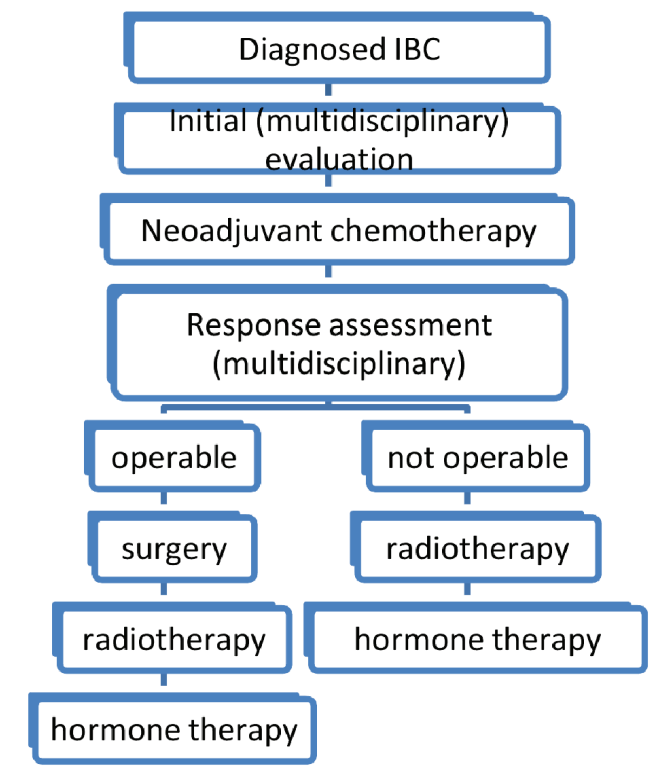

Figure 2. Diagram of therapeutic strategy of inflammatory breast cancers.

\section{Surgery}

Surgery plays an important role in the multimodal treatment of IBC. The standard procedure is a radical mastectomy with axillary dissection. The involvement of axillary lymph nodes is noted in $55 \%$ to $85 \%$ in IBC at the time of diagnosis [48]. The purpose of the surgery must be complete resection of the residual disease. Conservative surgery and sentinel lymph node biopsy must be avoided [49]. Several studies have demonstrated that pCR predicts of higher survival as well as good local control [50]. In the metastatic disease, surgery is indicated only for uncontrolled hemorrhage.

\section{Radiotherapy}

The standard approach for patients with IBC after mastectomy is radiotherapy. There are no specific doses for IBC. To evaluate the most effective radiation dose effect, 32 patients who were treated with radiotherapy twice a day at a total dose of 60 Gy were compared with the results for the 39 patients treated twice daily for a total dose of $66 \mathrm{~Gy}$. A better rate of locoregional control was achieved in the high-dose group than in the standard-dose group ( $84 \%$ vs. $58 \%$ at 5 years, $77 \%$ vs. $58 \%$ at 10 years) [51]. Short-term and long-term analyses of toxic reactions to this treatment were examined, the higher risk of developing late complications was observed in the high-dose group than in the standard-dose group (29\% vs. 15\%, respectively). This approach is not yet validated [52].

Preoperative radiotherapy trials have shown that the rate of complications is higher in patients who receive preoperative radiotherapy and the risk of postoperative complications is dose-dependent [53]. In MD Anderson preoperative radio- 
therapy trials evaluating local 5-year control and non-distant metastasis-free survival for 42 patients with IBC, the rates were $75 \%$ and $20 \%$, respectively, and eight patients survived without distant metastasis for more than 40 months (unpublished data). However, the higher rate of complications has been reported in patients who received preoperative radiation. Preoperative concomitant chemoradiotherapy is not indicated in breast cancer as in other cancers [54].

\section{Conclusions}

The diagnosis of IBC remains above all a clinical diagnosis supported by a histological evidence of infiltrating carcinoma, and the therapeutic approach can only be multidisciplinary. The ability to identify new targeted therapies allows us to control the aggressive phenotype of IBC. Molecular biology and genomics are very likely to play an important role in the diagnosis and management of IBC.

\section{Conflict of Interest}

The authors have no conflict of interest to declare.

\section{Author Contributions}

All authors have been involved in the process of writing and have approved the final manuscript.

\section{References}

1. Hance KW, Anderson WF, Devesa SS, Young HA, Levine $\mathrm{PH}$. Trends in inflammatory breast carcinoma incidence and survival: the surveillance, epidemiology, and end results program at the National Cancer Institute. J Natl Cancer Inst. 2005;97(13):966-975.

2. Cristofanilli M, Buzdar AU, Hortobagyi GN. Update on the management of inflammatory breast cancer. Oncologist. 2003;8(2):141-148.

3. Taylor G, Meltzer A. Inflammatory carcinoma of the breast. Am J Cancer. 1938;33:33-49.

4. Boussen H, Bouzaiene H, Ben Hassouna J, Gamoudi A, Benna F, Rahal K. Inflammatory breast cancer in Tunisia: reassessment of incidence and clinicopathological features. Semin Oncol. 2008;35(1):17-24.

5. Slaoui M, Zoure AA, Mouh FZ, Bensouda Y, El Mzibri M, Bakri Y, Amrani M. Outcome of inflammatory breast cancer in Moroccan patients: clinical, molecular and pathological characteristics of 219 cases from the National Oncology Institute (INO). BMC Cancer. 2018;18(1):713.

6. Soliman AS, Banerjee M, Lo AC, Ismail K, Hablas A, Seifeldin IA, Ramadan M, et al. High proportion of inflammatory breast cancer in the Population-based Cancer Registry of Gharbiah, Egypt. Breast J. 2009;15(4):432434.
7. Wingo PA, Jamison PM, Young JL, Gargiullo P. Population-based statistics for women diagnosed with inflammatory breast cancer (United States). Cancer Causes Control. 2004;15(3):321-328.

8. Chang S, Buzdar AU, Hursting SD. Inflammatory breast cancer and body mass index. J Clin Oncol. 1998;16(12):3731-3735.

9. Hirko KA, Soliman AS, Banerjee M, Ruterbusch J, Harford JB, Chamberlain RM, Graff JJ, et al. Characterizing inflammatory breast cancer among Arab Americans in the California, Detroit and New Jersey Surveillance, Epidemiology and End Results (SEER) registries (1988-2008). Springerplus. 2013;2(1):3.

10. Mourali N, Muenz LR, Tabbane F, Belhassen S, Bahi J, Levine PH. Epidemiologic features of rapidly progressing breast cancer in Tunisia. Cancer. 1980;46(12):27412746.

11. Ellis DL, Teitelbaum SL. Inflammatory carcinoma of the breast. A pathologic definition. Cancer. 1974;33(4):10451047.

12. Joseph Rabban, MD MPH Associate Professor UCSF Pathology Department. The New Edition (7th). AJCC staging system for breast cancer a summary of key changes. 2010.

13. Bonnier P, Charpin C, Lejeune C, Romain S, Tubiana N, Beedassy B, Martin PM, et al. Inflammatory carcinomas of the breast: a clinical, pathological, or a clinical and pathological definition? Int J Cancer. 1995;62(4):382385.

14. Goncalves A, Sabatier R, Charafe-Jauffret E, Gilabert M, Provansal M, Tarpin C, Extra JM, et al. [Triple-negative breast cancer: histoclinical and molecular features, therapeutic management and perspectives]. Bull Cancer. 2013;100(5):453-464.

15. Bertucci F, Finetti P, Rougemont J, Charafe-Jauffret E, Nasser V, Loriod B, Camerlo J, et al. Gene expression profiling for molecular characterization of inflammatory breast cancer and prediction of response to chemotherapy. Cancer Res. 2004;64(23):8558-8565.

16. Chaher N, Arias-Pulido H, Terki N, Qualls C, Bouzid $\mathrm{K}$, Verschraegen C, Wallace AM, et al. Molecular and epidemiological characteristics of inflammatory breast cancer in Algerian patients. Breast Cancer Res Treat. 2012;131(2):437-444.

17. Kertmen N, Babacan T, Keskin O, Solak M, Sarici F, Akin S, Arik Z, et al. Molecular subtypes in patients with inflammatory breast cancer; a single center experience. J BUON. 2015;20(1):35-39.

18. Hieken TJ, Murphy BL, Boughey JC, Degnim AC, Glazebrook KN, Hoskin TL. Influence of Biologic Subtype of Inflammatory Breast Cancer on Response to Neoadjuvant Therapy and Cancer Outcomes. Clin Breast Cancer. 2018;18(4):e501-e506.

19. DeSnyder SM, Mittendorf EA. Prospective feasibility trial of sentinel lymph node biopsy in the setting of inflammatory breast cancer. Clinical Breast Cancer. 2018;18(1):e73-e77

20. Resetkova E. Pathologic aspects of inflammatory breast carcinoma: part 1. Histomorphology and differential di- 
agnosis. Semin Oncol. 2008;35(1):25-32.

21. Amparo RS, Angel CD, Ana LH, Antonio LC, Vicente MS, Carlos FM, Vicente GP. Inflammatory breast carcinoma: pathological or clinical entity? Breast Cancer Res Treat. 2000;64(3):269-273.

22. Eiro N, Gonzalez L, Gonzalez LO, Fernandez-Garcia B, Lamelas ML, Marin L, Gonzalez-Reyes S, et al. Relationship between the inflammatory molecular profile of breast carcinomas and distant metastasis development. PLoS One. 2012;7(11):e49047.

23. Kleer CG, Zhang Y, Pan Q, van Golen KL, Wu ZF, Livant D, Merajver SD. WISP3 is a novel tumor suppressor gene of inflammatory breast cancer. Oncogene. 2002;21(20):3172-3180.

24. Kleer CG, van Golen KL, Braun T, Merajver SD. Persistent E-cadherin expression in inflammatory breast cancer. Mod Pathol. 2001;14(5):458-464.

25. Kowalski PJ, Rubin MA, Kleer CG. E-cadherin expression in primary carcinomas of the breast and its distant metastases. Breast Cancer Res. 2003;5(6):R217-222.

26. Lehman HL, Van Laere SJ, van Golen CM, Vermeulen PB, Dirix LY, van Golen KL. Regulation of inflammatory breast cancer cell invasion through Akt1/PKBalpha phosphorylation of RhoC GTPase. Mol Cancer Res. 2012;10(10):1306-1318.

27. Bieche I, Lerebours F, Tozlu S, Espie M, Marty M, Lidereau R. Molecular profiling of inflammatory breast cancer: identification of a poor-prognosis gene expression signature. Clin Cancer Res. 2004;10(20):6789-6795.

28. Kalluri R, Weinberg RA. The basics of epithelial-mesenchymal transition. J Clin Invest. 2009;119(6):1420-1428.

29. Polyak K, Weinberg RA. Transitions between epithelial and mesenchymal states: acquisition of malignant and stem cell traits. Nat Rev Cancer. 2009;9(4):265-273.

30. Van Laere SJ, Van der Auwera I, Van den Eynden GG, van Dam P, Van Marck EA, Vermeulen PB, Dirix LY. NFkappaB activation in inflammatory breast cancer is associated with oestrogen receptor downregulation, secondary to EGFR and/or ErbB2 overexpression and MAPK hyperactivation. Br J Cancer. 2007;97(5):659-669.

31. Dawood S, Merajver SD, Viens P, Vermeulen PB, Swain SM, Buchholz TA, Dirix LY, et al. International expert panel on inflammatory breast cancer: consensus statement for standardized diagnosis and treatment. Ann Oncol. 2011;22(3):515-523.

32. Chantal Feger, Isabelle Leconte, Latifa Fellah. Imagerie des cancers du sein inflammatoire. Imagerie de la Femme. 2006;16:181-1903.

33. Yang WT, Le-Petross HT, Macapinlac H, Carkaci S, Gonzalez-Angulo AM, Dawood S, Resetkova E, et al. Inflammatory breast cancer: PET/CT, MRI, mammography, and sonography findings. Breast Cancer Res Treat. 2008;109(3):417-426.

34. Gunhan-Bilgen I, Ustun EE, Memis A. Inflammatory breast carcinoma: mammographic, ultrasonographic, clinical, and pathologic findings in 142 cases. Radiology. 2002;223(3):829-838.

35. Carkaci S, Macapinlac HA, Cristofanilli M, Mawlawi O, Rohren E, Gonzalez Angulo AM, Dawood S, et al. Ret- rospective study of $18 \mathrm{~F}-\mathrm{FDG} \mathrm{PET} / \mathrm{CT}$ in the diagnosis of inflammatory breast cancer: preliminary data. J Nucl Med. 2009;50(2):231-238.

36. Bozzetti F, Saccozzi R, De Lena M, Salvadori B. Inflammatory cancer of the breast: analysis of 114 cases. J Surg Oncol. 1981;18(4):355-361.

37. Lamb CC, Eberlein TJ, Parker LM, Silver B, Harris JR. Results of radical radiotherapy for inflammatory breast cancer. Am J Surg. 1991;162(3):236-242.

38. Ueno NT, Buzdar AU, Singletary SE, Ames FC, McNeese MD, Holmes FA, Theriault RL, et al. Combined-modality treatment of inflammatory breast carcinoma: twenty years of experience at M. D. Anderson Cancer Center. Cancer Chemother Pharmacol. 1997;40(4):321-329.

39. Cristofanilli M, Buchholz TA. Proceedings of the First International Inflammatory Breast Cancer Conference. Cancer. 2010;116(11 Suppl):2729.

40. Cristofanilli M, Buzdar AU, Sneige N, Smith T, Wasaff B, Ibrahim N, Booser D, et al. Paclitaxel in the multimodality treatment for inflammatory breast carcinoma. Cancer. 2001;92(7):1775-1782.

41. Baldini E, Gardin G, Evagelista G, Prochilo T, Collecchi $\mathrm{P}$, Lionetto R. Long-term results of combined-modality therapy for inflammatory breast carcinoma. Clin Breast Cancer. 2004;5(5):358-363.

42. Parton M, Dowsett M, Ashley S, Hills M, Lowe F, Smith IE. High incidence of HER-2 positivity in inflammatory breast cancer. Breast. 2004;13(2):97-103.

43. Gianni L, Eiermann W, Semiglazov V, Manikhas A, Lluch A, Tjulandin S, Zambetti M, et al. Neoadjuvant chemotherapy with trastuzumab followed by adjuvant trastuzumab versus neoadjuvant chemotherapy alone, in patients with HER2-positive locally advanced breast cancer (the NOAH trial): a randomised controlled superiority trial with a parallel HER2-negative cohort. Lancet. 2010;375(9712):377-384.

44. Gianni L, Pienkowski T, Im YH, Roman L, Tseng LM, Liu MC, Lluch A, et al. Efficacy and safety of neoadjuvant pertuzumab and trastuzumab in women with locally advanced, inflammatory, or early HER2-positive breast cancer (NeoSphere): a randomised multicentre, openlabel, phase 2 trial. Lancet Oncol. 2012;13(1):25-32.

45. Schneeweiss A, Chia S, Hickish T, Harvey V, Eniu A, Hegg R, Tausch C, et al. Pertuzumab plus trastuzumab in combination with standard neoadjuvant anthracyclinecontaining and anthracycline-free chemotherapy regimens in patients with HER2-positive early breast cancer: a randomized phase II cardiac safety study (TRYPHAENA). Ann Oncol. 2013;24(9):2278-2284.

46. Cristofanilli M, Boussen $\mathrm{H}$, Baselga J, et al. AphaseII combination study of lapatinib and paclitaxel as a neoadjuvant therapy in patients with newly diagnosed inflammatory breast cancer (IBC) [abstract 1]. Breast Cancer Res Treat. 2006;100(suppl 1).

47. Wedam SB, Low JA, Yang SX, Chow CK, Choyke P, Danforth D, Hewitt SM, et al. Antiangiogenic and antitumor effects of bevacizumab in patients with inflammatory and locally advanced breast cancer. J Clin Oncol. 2006;24(5):769-777. 
48. Fleming RY, Asmar L, Buzdar AU, McNeese MD, Ames FC, Ross MI, Singletary SE. Effectiveness of mastectomy by response to induction chemotherapy for control in inflammatory breast carcinoma. Ann Surg Oncol. 1997;4(6):452-461.

49. Bristol IJ, Woodward WA, Strom EA, Cristofanilli M, Domain D, Singletary SE, Perkins GH, et al. Locoregional treatment outcomes after multimodality management of inflammatory breast cancer. Int J Radiat Oncol Biol Phys. 2008;72(2):474-484.

50. Kell MR, Morrow M. Surgical aspects of inflammatory breast cancer. Breast Dis. 2005;22:67-73.

51. Liao Z, Strom EA, Buzdar AU, Singletary SE, Hunt K, Allen PK, McNeese MD. Locoregional irradiation for inflammatory breast cancer: effectiveness of dose escalation in decreasing recurrence. Int J Radiat Oncol Biol
Phys. 2000;47(5):1191-1200.

52. Pisansky TM, Schaid DJ, Loprinzi CL, Donohue JH, Schray MF, Schomberg PJ. Inflammatory breast cancer: integration of irradiation, surgery, and chemotherapy. Am J Clin Oncol. 1992;15(5):376-387.

53. Krajcovicova I, Boljesikova E, Sandorova M, Zavodska A, Zemanova M, Chorvath M, Ondrus D. Preoperative radiotherapy of locally advanced rectal cancer: clinical outcome of short-course and long-course treatment with or without concomitant chemotherapy. Klin Onkol. 2012;25(5):364-369.

54. Damast S, Ho AY, Montgomery L, Fornier MN, Ishill N, Elkin E, Beal K, et al. Locoregional outcomes of inflammatory breast cancer patients treated with standard fractionation radiation and daily skin bolus in the taxane era. Int J Radiat Oncol Biol Phys. 2010;77(4):1105-1112. 